\title{
GRANDES CAPTURAS FLUVIAIS NO BRASIL: SÍNTESE DAS NOVAS DESCOBERTAS
}

\author{
ANDRÉ AUGUSTO RODRIGUES SALGADO ${ }^{(1)}$, LUÍS FELIPE SOARES CHEREM ${ }^{(2)}$ \& MICHAEL VINÍCIUS \\ DE SORDI ${ }^{(3)}$
}

Resumo:

\begin{abstract}
Capturas fluviais foram pouco investigadas no Brasil e apenas recentemente essa situação se alterou e sua ocorrência e feições correlatas foram sistematicamente estudadas para as grandes bacias fluviais não Amazônicas. Esse artigo sintetiza os principais resultados obtidos nos últimos cinco anos e apresenta a diversidade de magnitude e morfológica em seis capturas fluviais ao longo de quatro divisores entre as principais bacias hidrográficas do Brasil. Os resultados indicam que o nível de base, seguido da litoestrutura e da tectônica, constituem os fatores determinantes para ocorrência desses processos. Indicam ainda que as bacias hidrográficas atlânticas estão pirateando áreas das ditas continentais - Paraná e São Francisco - e que essa pirataria acelera o recuo erosivo do escarpamento da margem passiva sul-americana. Por fim, determinaram que as capturas causam a dissecação da rede de drenagem capturada, invertem o fluxo dos canais logo a jusante e, por fim, promovem o rebaixamento geral do relevo pirateado.
\end{abstract}

Palavras-chave: Captura Fluvial, Brasil, Grandes Divisores Hidrográficos, Canal Fluvial.

\begin{abstract}
:
Large fluvial captures in Brazil: synthesis of new discoveries

River captures have barely been studied in Brazil, and only recently the process and correlated features have been systematically studied for non-Amazonian major river basins. This paper synthesizes the main results obtained for the last five years and presents the diversity in magnitude and morphology of six river captures along the four divider of Brazilian-major river basins. The results indicate that the base level, followed by the lithostructure and tectonics, are the determining factors for the occurrence of these processes. They also indicate that the Atlantic basins are pirating areas of the continental ones - Paraná and São Francisco - and that this piracy accelerates the erosive retreat of the South American passive margin escarpment. Finally, they determined that the captures cause the dissection of the drainage network, invert the flow of the channels shortly downstream, and finally, promote the general lowering of the pirated relief.
\end{abstract}

Keywords: River capture, Brazil, Major Basin Dividers, Fluvial Channel.

\section{INTRODUÇÃO}

O Brasil é um país de dimensões continentais, de clima predominantemente tropical e que possui em seu interior algumas das maiores redes de drenagem do mundo (Figura 1). Rios como o Amazonas, Paraná, São Francisco e Araguaia/Tocantins estão entre os 50 maiores do globo em termos de extensão e de descarga hídrica. Suas bacias hidrográficas drenam milhões de $\mathrm{km}^{2} \mathrm{e}$ recobrem boa parte do território da América do Sul. Porém, além deles, existe uma série de canais de menor dimensão que, junto aos seus afluentes, formam bacias hidrográficas que, não raro, ultrapassam os $50.000 \mathrm{~km}^{2}$ como, por exemplo, as dos rios Uruguai, Paraíba do Sul, Doce, Jequitinhonha, de Contas, Paraguaçu, Jaguaribe, Parnaíba, Itapecuru e Mearim. De modo geral, o divisor entre essas bacias hidrográficas é constituído por amplos planaltos e chapadas ou elevadas serras. Há também casos onde o divisor hidrográfico se caracteriza morfologicamente como um proeminente degrau no relevo onde uma bacia drena o planalto que constitui o piso superior e a outra a escarpa e o piso inferior. De qualquer forma, a maior parte desses grandes divisores hidrográficos possui uma característica em comum: são coincidentes com os limites entre os compartimentos geotectônicos que compõe o território brasileiro. Compartimentos esses herdados dos eventos Transamazônico e, principalmente, Brasiliano, que teve seu auge há aproximadamente 600 milhões de anos. Logo, nota -se que mesmo para um país localizado longe das margens ativas de placas tectônicas e onde o último evento compressional ocorreu no Pré-

\footnotetext{
(1) Professor Associado do Departamento de Geografia da Universidade Federal de Minas Gerais - Avenida Antônio Carlos 627, Pampulha, Campus Universitário - Instituto de Geociências - Belo Horizonte MG - CEP: 31270-901. Telefone: 5531 3409-5462. aarsalgadoufmg@gmail.com

${ }^{(2)}$ Professor Adjunto do Instituto de Estudos Sócio-Ambientais da Universidade Federal de Goiás - Campus Samambaia - Goiânia/GO - CEP: 74.001-970 luis.cherem@gmail.com

${ }^{(3)}$ Doutorando do Programa em Pós-graduação em Geografia da Universidade Federal de Minas Gerais - Avenida Antônio Carlos 627, Pampulha, Campus Universitário - Instituto de Geociências - Belo Horizonte/MG - CEP: 31270-901. michael.sordi@gmail.com
} 
cambriano, as estruturas herdadas ainda parecem ser determinantes para a configuração das atuais bacias hidrográficas.

Apesar deste elevado número de bacias e divisores hidrográficos, estudos acerca de capturas fluviais foram raros no Brasil. Estes se iniciam com aquele que, ainda hoje, constitui o trabalho referência da Geomorfologia Brasileira sobre o tema: Ab' Saber (1957). Esta pesquisa, após tantos anos, ainda se mantêm como referência em razão de que, além de ser o primeiro trabalho do gênero no país, conseguiu identificar uma grande captura fluvial. Grande captura essa que fez com que as áreas de nascente do Rio Tietê - um importante afluente do Rio Paraná no Estado de São Paulo - se tornassem as do rio Paraitinga que é um dos dois formadores do Rio Paraíba do Sul. Porém, após essa pesquisa, nos cinquenta anos subsequentes foram raras as que se debruçaram sobre a mesma temática. Dentre essas poucas merece destaque a conduzida por Santos (1999) que comprovou que o Rio Grande - principal formador do Rio Paraná na região do Maciço do Itatiaia pirateou áreas do Rio Aiuruoca que é o seu mais importante afluente de alto curso. Merece igual destaque as pesquisas realizadas por Oliveira \& Queiroz Neto (2007) que identificaram capturas fluviais na Serra do Mar e as de Gontijo (1999) e Castanheira et al. (2006) que estudaram esse processo no Vale do Paraíba do Sul. Entretanto, à exceção do trabalho de $\mathrm{Ab}$ ' Saber (1957), nenhum desses outros estudos se dedicou a pesquisar o fenômeno das capturas fluviais em importantes divisores hidrográficos.

Esta situação só se alterou após o ano de 2012 quando o Grupo de Pesquisa em Geomorfologia e Recursos Hídricos da Universidade Federal de Minas Gerais e investigadores a ele associados, começou a, sistematicamente, estudar a evolução do relevo dos grandes divisores hidrográficos do Brasil $\mathrm{e}$, durante essa investigação, identificou inúmeros e importantes processos de captura fluvial no interior dessas áreas (Fig. 1). Neste contexto, o presente artigo, através de revisão bibliográfica, apresenta uma síntese do que este grupo pesquisou e do que reconheceu das grandes capturas fluviais que modificaram a dinâmica erosiva e os fluxos de matéria e energia entre algumas das principais bacias hidrográficas do Brasil.

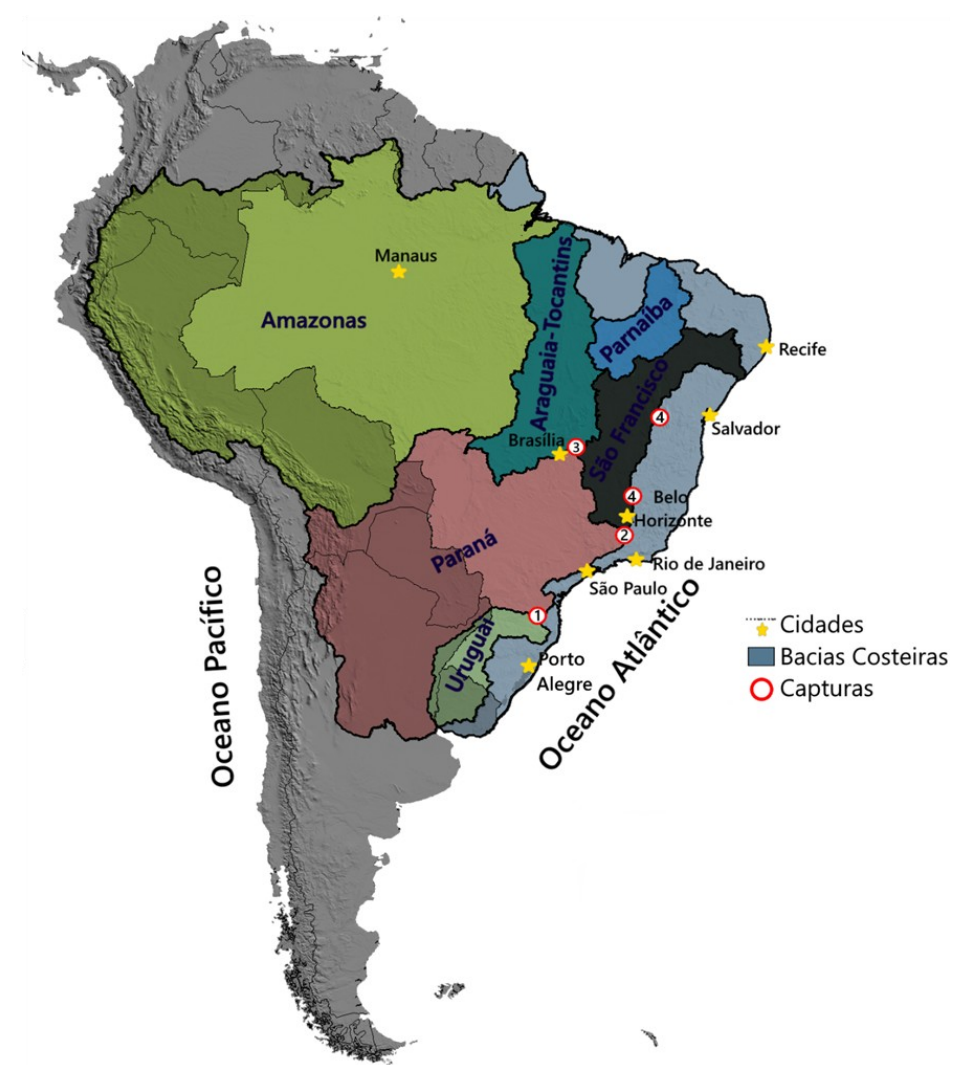

Fig. 1. As grandes Bacias Hidrográficas do Brasil e áreas de pesquisa: (1) Tríplice divisor hidrográfico Itajaí-Açu/Uruguai/Paraná; (2) Região dos divisores hidrográficos Paraíba do Sul/Doce/São Francisco/Paraná; (3) Extremo Nordeste do divisor hidrográfico Paraná/São Francisco e; (4) Divisor Hidrográfico do São Francisco/Doce na Serra do Espinhaço Meridional e São Francisco/ Paraguaçu na Serra do Espinhaço Setentrional.

Fig. 1. The large catchments of Brazil and research areas: (1) Triple hydrographic divisor Itajaí-Açu/Uruguay/Paraná; (2) Region of the hydrographic divisors Paraíba do Sul/Doce/São Francisco/Paraná; (3) Northeast end hydrographic divisor of the Paraná/São Francisco; (4) Hydrographic Divisor of the São Francisco/ Doce in the Southern Espinhaço Mountain and São Francisco/Paraguaçu in the Northern Espinhaço Mountain. 


\section{GRANDES CAPTURAS FLUVIAIS DO TERRITÓRIO BRASILEIRO}

\subsection{Bacia Hidrográfica do Itajaí-Açu versus Paraná e Uruguai na Serra Geral}

No sudeste/sul do Brasil a escarpa principal que representa o limite entre as bacias Atlânticas e as bacias continentais é a Serra do Mar que, por sua vez, também constitui o divisor entre os compartimentos Geotectônico-Geomorfológico da Bacia do Paraná com o Antigo Orógeno Mantiqueira (ALMEIDA et al., 1981). No entanto, no Estado de Santa Catarina a Serra do Mar foi rompida pelo rio Itajaí-Açu e hoje suas cabeceiras se situam na Serra Geral, no interior do Planalto Catarinense, aproximadamente $200 \mathrm{~km}$ em direção ao continente (Fig. 2). Ali, em plena Bacia Sedimentar do Paraná, a Serra Geral constitui o tríplice divisor entre as bacias hidrográficas dos rios Itajaí-Açu, Paraná (Iguaçu) e Uruguai (Fig. 2).

Nessa área, onde o principal processo evolutivo é a dissecação provocada pela redehidrográfica tendo por controle nível de base, os tributários do Rio Itajaí-Açu pirateiam áreas das bacias vizinhas: Paraná (Iguaçu) e Uruguai. Este processo ocorre, pois a Bacia Hidrográfica do Rio Itajaí-Açu drena, topograficamente, um patamar inferior (com elevações entre $400-800 \mathrm{~m}$ ) localizado a leste e sustentado por rochas

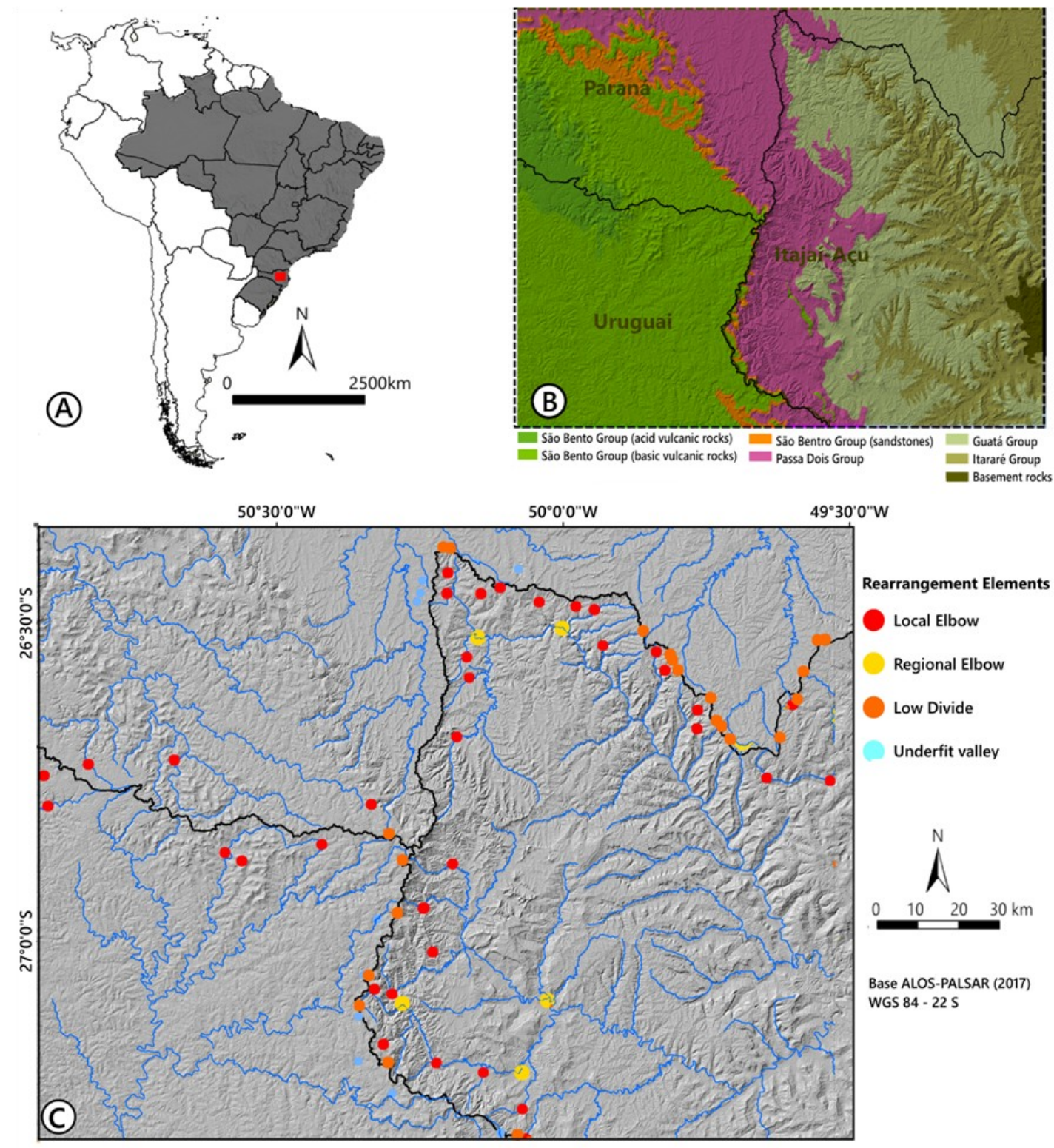

Fig. 2. Localização e capturas fluviais no tríplice divisor hidrográfico Itajaí-Açu/Paraná/Uruguai. Fig. 2. Location and river captures in the triple hydrographic divisor Itajaí-Açu/Paraná/Uruguay. 
sedimentares do Paleozóico (Fig. 2) (SoRDI et al., 2016). Já a oeste, o Planalto Catarinense se divide entre: (1) o sector norte (drenado pelos afluentes do rio Paraná) e; (2) o sul, drenado pelos afluentes do rio Uruguai. No sector norte se identificam três sub-patamares: i) a oeste o patamar mais elevado drenado pelo rio Timbó onde rochas vulcânicas mesozoicas da Formação Serra Geral afloram $(1000-1200 \mathrm{~m} \mathrm{~m})$; ii) na região central onde um patamar mais baixo $(1000-600 \mathrm{~m})$ é drenado pelo rio Canoinhas sustentado por rochas sedimentares do Grupo Passa Dois (Paleozóico) e um patamar intermediário (800-1000 m) sustentado por rochas do Grupo Guatá (Paleozóico) (SoRDI et al., 2016). A sul, onde drenam os afluentes do rio Uruguai, as rochas predominantes são vulcânicas da Formação Serra Geral e constituem um patamar mais elevado $(600-1200 \mathrm{~m})$. Ali os vales dos rios principais Marombas e Correntes - comandam a dissecação (Fig. 2) (SorDI et al., 2016).

As pesquisas sobre a influência dos processos hidrográficos e capturas fluviais na área (SORDI et al., 2015a, b; Sordi et al., 2016) mostram que os tributários do rio Itajaí-Açu, por possuírem nível de base mais baixo, perfil topográfico mais declivoso e, consequentemente, maior poder de dissecação, recuaram por erosão remontante em direção ao planalto (a oeste) e piratearam áreas do planalto que anteriormente drenava em direção as bacias interioranas (Fig. 2 e 3). De fato, morfologicamente é fácil perceber grandes e pequenas capturas fluviais ao longo da borda da escarpa que demarca o limite entre a Bacia Hidrográfica do Rio Itajaí-Açu - piso inferior - das bacias dos rios Paraná (Iguaçu) e Uruguai - piso superior (Fig. 3).

Assim estes dados mostram que o mecanismo principal de evolução na área do tríplice divisor é o recuo da escarpa para oeste devido ao avanço remontante dos canais que drenam a escarpa da Serra Geral (Fig. 2 e 3). Este recuo se aproveita de lineamentos estruturais e é controlado por knickpoints. A influência morfoestrutural sob o processo erosivo se manifesta nas áreas onde ocorrem maior densidade de canais abandonados e decapitados (SoRDI et al., 2015b), as quais correspondem aquelas áreas onde há maior densidade de lineamentos estruturais e knickpoints. A litoestrutura também possui importância na diferenciação da forma transversal, a partir do padrão de fraturamento e acamamento (SORDI et al., 2015b).

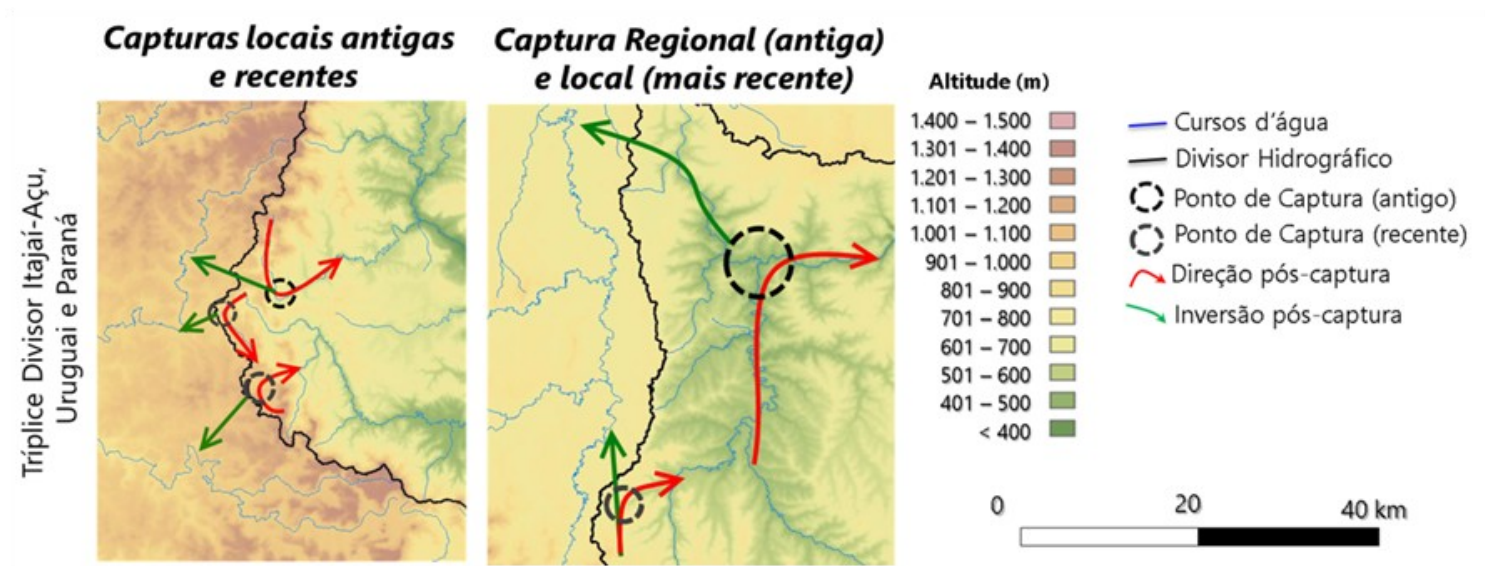

Fig. 3. Exemplos de diferentes gerações de capturas no tríplice divisor hidrográfico Itajaí-Açu/Paraná/Uruguai. Fig. 3. Examples of different generations of captures in the triple hydrographic divisor Itajaí-Açu / Paraná / Uruguay.

\subsection{Capturas fluviais do sudeste do Estado de Minas Gerais}

O relevo do Sudeste do Brasil, especificamente nas proximidades da coordenada $43^{\circ}$ e $-21^{\circ}$, foi desenvolvido a partir da erosão de (Salgado et al., 2015): (i) terrenos graníticogreenstone proterozóicos do compartimento Geotectônico-Geomorfológico do Cráton do São Francisco e (ii) remanescentes de embasamento cristalino do compartimento GeotectônicoGeomorfológico do Antigo Orógeno da Mantiqueira. Essas áreas são drenadas pelas bacias hidrográficas dos Rios Paraná a sudoeste $(1.200 \mathrm{~m}$ de altitude média), São Francisco a noroeste $(1.000 \mathrm{~m})$, Doce a nordeste $(800 \mathrm{~m})$, e Paraíba do Sul a sudeste $(500 \mathrm{~m})$. Regionalmente, essas bacias correspondem a planaltos escalonados e divididos por escarpas erosivas (Figura 4), onde predomina um relevo mamelonar (mar de morros).

Ao longo dos interflúvios entre as bacias hidrográficas dos rios São Francisco, Paraná, Doce e Paraíba do Sul, são observadas três mesocapturas fluviais (CHEREM et al., 2013), da ordem de $10^{1} \mathrm{~km}^{2}$ (Fig. 4). Apesar dessa semelhança na magnitude espacial, elas apresentam diferentes características morfológicas em suas encostas e planícies, resultantes da diversidade de estágios evolutivos 

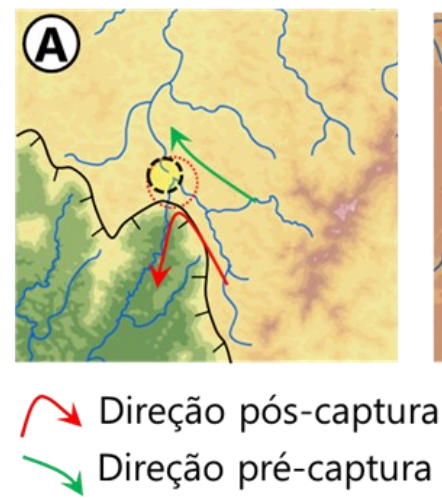
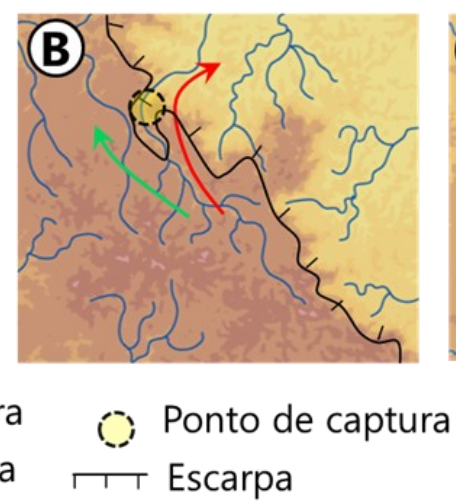
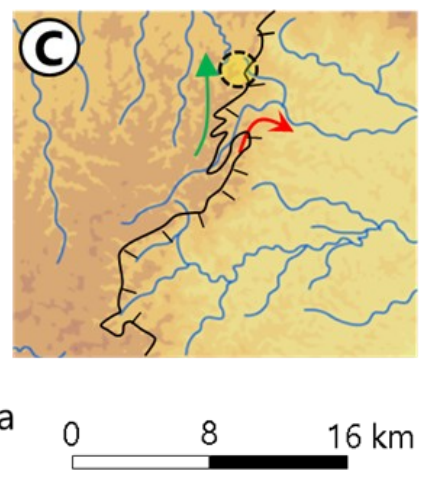

Fig. 4. As capturas fluviais do sudeste do Estado de Minas Gerais. Fig 4. The river captures in the southeast of the State of Minas Gerais.

atingidos. Todas drenam sobre rochas graníticas e, em todas elas, é possível identificar ocorrência de um vale decapitado (beheaded valley) com canal desajustado (underfit stream) e também um vale seco, por onde o rio pirateado costumava fluir (CHEREM et al., 2013).

A captura fluvial da bacia do Rio Paraíba do Sul sobre a bacia do Rio Doce transpõe uma escarpa erosiva com cerca de $450 \mathrm{~m}$ de altura, tendo área de $55,4 \mathrm{~km}^{2}$ (CHEREM et al., 2013). Suas encostas e planícies mantêm características semelhantes àquelas de áreas não pirateadas. $\mathrm{O}$ reafeiçoamento da paisagem se restringe, portanto, ao trecho do vale diretamente afetado pela captura, tendo havido a incisão fluvial de $\sim 1 \mathrm{~m}$ com o abandono dos depósitos fluviais de planície e formando um terraço fluvial do tipo embutido (Fig. 5). Nessa captura, o canal captor ainda drena sobre a escarpa em sua posição original (CHEREM et al., 2013).

A captura fluvial da bacia do Rio Doce sobre o Rio Paraná tem $66,2 \mathrm{~km}^{2}$, cruzando uma escarpa erosiva de $300 \mathrm{~m}$ de altura (SALGADO et al., 2012). A parte montante de suas encostas mantêm características semelhantes àquelas não capturadas e a incisão fluvial se restringe à planície com incisão fluvial até $4 \mathrm{~m}$. Já as encostas da porção jusante estão reafeiçoada pela incisão fluvial que atinge $50 \mathrm{~m}$ de um canal com leito rochoso (Fig. 5). O recuo da escarpa é de cerca de $1,5 \mathrm{~km}$ de sua posição anterior da captura (SALGADO et al., 2012).

A captura fluvial da Bacia do Rio Doce sobre o Rio São Francisco tem, por sua vez, $22,4 \mathrm{~km}^{2}$ e cruza uma escarpa erosiva de $250 \mathrm{~m}$ de altura (CHEREM et al., 2013). Essa captura já está intensamente reafeiçoada e apenas as encostas das cabeceiras mais a montante e aquelas controladas por knick points (cachoeiras) mantiveram suas formas antigas (Fig. 5). Nela a erosão fluvial remontante foi intensa o suficiente para não mais drenar sobre a escarpa que recuou cerca de $3,5 \mathrm{~km}$ de sua posição anterior da captura (CHEREM et al., 2013).

A análise morfológica comparativa dessas capturas permite entendê-las em um cenário de morfodinâmica ativa e progressiva. Assim, a diversidade morfológica e morfográfica de canais e encostas entre essas capturas é resultante de uma sucessão de momentos evolutivos de um processo continuo de rebaixamento do relevo e recuo de escarpas. Para todas as três capturas, foram mensuradas as taxas de erosão através do isótopo cosmogênico ${ }^{10} \mathrm{Be}$ (CHEREM et al., 2012; SALGADO et al., 2012) que indicam que as bacias capturadas apresentam taxas erosivas intermediárias frente as taxas dos frontes dos escarpamentos - elevadas - e as do planaltos superiores - baixas. Especialmente, a captura mais recente e com menor alteração morfológica (do Rio Paraíba do Sul sobre o Rio Doce) foi datada holocênica, com início posterior a $9.000 \pm 800$ anos e escalonamento de terraços também posterior a $1.700 \pm 200$ (OLIVEIRA, 2012). Pôde-se concluir que as capturas analisadas, muito embora apresentem características distintas, estão associadas a diferentes estágios de evolução progressiva onde as bacias que drenam os planaltos inferiores ampliam suas áreas pirateando canais fluviais de terceira e quarta ordens.

Essa dinâmica é sintetizada em um esquema evolutivo de capturas fluviais existentes em planaltos escalonados analisados composto por quatro estágios (Fig. 5): (1) o canal captor, que antes da captura correspondia a uma cabeceira de drenagem (ordem zero), cruza a crista e alcança a planície fluvial de um outro canal, (2) a cabeceira de drenagem passa a drenar parte da água da planície fluvial, aumentando seu volume de água, o que acelera o processo de avanço da cabeceira de drenagem, levando a captura do canal do planalto superior, (3) após a instalação da captura, há um intenso rebaixamento do relevo pela incisão fluvial do entorno desse ponto de captura exumando os afloramentos rochosos e recuando a frente da escarpa, (4) o processo de rebaixamento do relevo progride e remodela as encostas mais distantes do ponto de captura. 


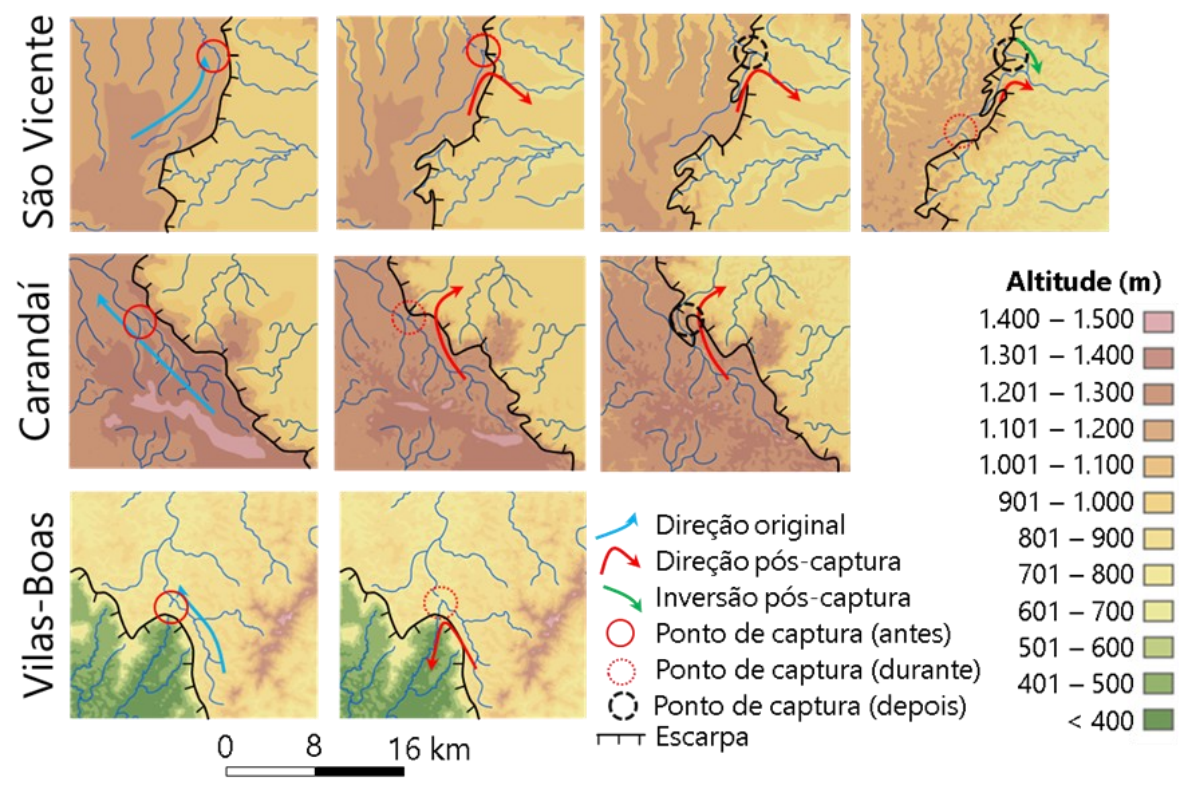

Fig. 5. Esquema de Evolução das capturas fluviais do Sudeste do Estado de Minas Gerais. (FONTE: CHEREM et al. 2013).

Fig. 5. Evolution scheme of the river captures in the Southeast of the State of Minas Gerais. (SOURCE: CHEREM et al., 2013).

\subsection{Captura do Distrito Federal (Brasília)}

Em geral, as capturas fluviais mais estudadas no Brasil são mesocapturas, da ordem de da ordem de $10^{2} \mathrm{~km}^{2}$, e estão localizadas nos interflúvios que dividem as bacias hidrográficas costeiras das interiores, estando, assim, associadas a morfodinâmica das escarpas erosivas de margens passivas. Por sua vez, no interior do Brasil Central (Distrito Federal), no limite entre as bacias dos Rio São Francisco e Paraná, destaca-se uma macrocaptura fluvial com área em torno de $3.500 \mathrm{~km}^{2}$. A região corresponde a um relevo aplainado da associado à superfície de aplainamento Sulamericana (planalto Central Goiano, com altitude média de $900 \mathrm{~m}$ na região), para a bacia Rio do Paraná, e a residuais da superfície Velhas (Depressão Sanfranciscana com altitude média de $600 \mathrm{~m}$ na região), para a bacia do Rio São Francisco, ambas elaboradas a partir da degradação do Orógeno Brasiliano da Faixa Brasília, pertencente à Província Geotectônica Tocantins (SAlGADO et al., 2015) (Fig. 6).

A captura ocorreu em um canal de $6^{\text {a }}$ ordem hierárquica (Strahler, 1957) com elevada vazão e potência de canal (stream power). Essa alta energia se reflete em uma incisão de $30 \mathrm{~m}$, desequilibrando as encostas e planícies com grande intensidade nos médio e baixo trecho da bacia hidrográfica capturada. Assim, as encostas desses trechos foram remodeladas com feições erosivas aceleradas pela erosão linear e areal, e também com a instalação de processos gravitacionais que se superimpõem na paisagem. As planícies, ao mesmo tempo que foram remodeladas pela incisão fluvial, passaram a receber maior volume de sedimentos. Em geral, no trecho superior da bacia, foram mantidas as características originais de encostas e planícies, muito embora, localmente, sejam observadas feições erosivas lineares e areais. Toda a bacia capturada e a sua porção não capturada tem suas encostas recobertas por material indiferenciado do Quaternário. Assim, apesar de suas proporções, a captura ainda está em seu estágio evolutivo inicial.

Por sua vez, essa macrocaptura fluvial teve efeitos no relevo da bacia captora, já que o incremento do volume de água no canal captor aumentou sua energia, induzindo a incisão fluvial e o aumento da densidade de drenagem e da dissecação das encostas.

\subsection{Bacias Hidrográficas Atlânticas versus São Francisco na Serra do Espinhaço}

A Serra do Espinhaço constitui importante divisor hidrográfico entre a Bacia do Rio São Francisco e as bacias Atlânticas do leste brasileiro - destaque para as do Doce, Jequitinhonha, Contas e Paraguaçu (Fig. 1). Representa ainda o limite entre o compartimento GeotectônicoGeomorfológico do Cráton do São Francisco com o antigo Orógeno da Mantiqueira (SALGADO et al., 2015). Apesenta-se morfologicamente como um planalto dissecado e pontilhado de picos e escarpas. Em termos litológicos, em sua porção meridional - limite entre São Francisco com Doce/ Jequitinhonha - são amplamente predominantes os quartzitos (ALMEIDA \& RENGER, 2002; MAGALHÃES JÚNIOR et al., 2015) que apresentam 


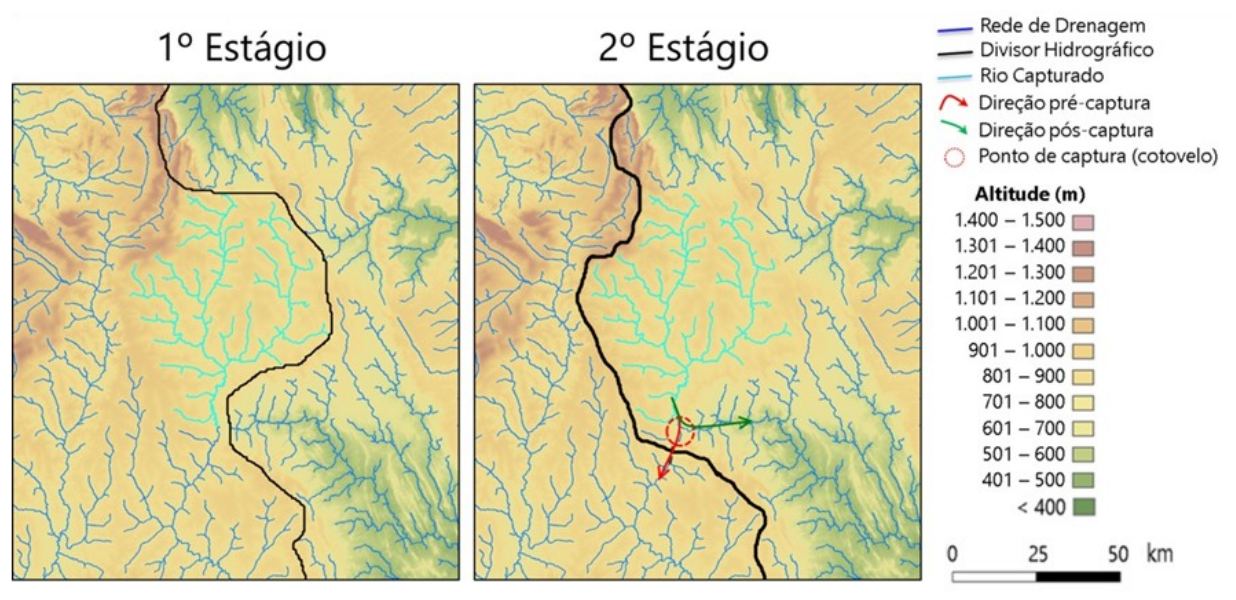

Fig. 6. A captura do Distrito Federal (Brasília).

Fig. 6. The river capture on the Federal District (Brasília).

para leste a principal direção de mergulho de suas camadas. Já em sua porção setentrional - limite entre São Francisco com Contas/Paraguaçu embora sejam comuns os quartzitos, ocorrem com certa frequência meta-arenitos e outros litotipos mais frágeis (LimA \& NolASCO, 2015). Esta diferença litológica é proveniente do fato da Serra do Espinhaço durante o Brasiliano ter, em sua porção sul, sofrido maiores esforços tectônicos do que a norte.

Diversas pesquisas geomorfológicas já foram realizadas na Serra do Espinhaço, tanto na meridional como na setentrional. Entretanto, poucas se inquietaram em investigar processos de captura fluvial. Exceção foram as pesquisas de Barreto et al. (2013) na porção sul e a de Cordeiro (2017) na porção norte, notadamente na área reconhecida como Chapada Diamantina-Serra do Sincorá.

Barreto et al. (2013) mensurou as taxas quaternárias de denudação - via isótopo cosmogênico ${ }^{10} \mathrm{Be} \quad-$ de diversas bacias hidrográficas localizadas no interflúvio entre o Rio São Francisco com os rios Doce e Jequitinhonha (Fig. 1). Seus resultados demonstraram que os quartzitos que compõe a Serra do Espinhaço Meridional são tão resistentes frente aos processos erosivos/denudacionais - taxas sempre inferiores a $5 \mathrm{~m} / \mathrm{Ma}$ - que, por consequência, não ocorrem na região relevantes capturas fluviais. Logo, graças a essa elevada resistência litológica, são raras grandes alterações na paisagem e nos fluxos de matéria e energia entre as bacias hidrográficas.

Situação oposta foi encontrada para a Serra do Espinhaço Setentrional. Cordeiro (2017) através de análises morfológicas demonstrou que o Rio Paraguaçu e seu principal afluente, o Rio Santo Antônio, durante o Terciário Superior erodiram e romperam as escarpas leste da Chapada Diamantina-Serra do Sincorá e capturaram as extensas áreas que compõe o interior de sua sinclinal (Fig. 7). Áreas essas que, em fase anterior, eram drenadas em direção ao Rio São Francisco. Trata-se, segundo a escala proposta por Summerfield (1991), de uma macro captura fluvial, pois abrangeu mais de mil quilômetros quadrados.

O mais interessante nesse processo é que ele ocorreu em dois estágios: No primeiro, uma das paleonascentes do Rio Santo Antônio, aproveitando-se de lineamentos estruturais, rompeu as escarpas localizadas a nordeste da Chapada Diamantina-Serra do Sincorá e, ao penetrar no interior da sinclinal, capturou toda a drenagem que, anteriormente, se dirigia para noroeste em direção ao Rio São Francisco (Fig. 7). Posteriormente, foi a vez de uma paleonascente do Rio Paraguaçu, também aproveitando-se de estruturas, romper essas mesmas escarpas mais ao sul e assim interceptar toda a drenagem localizada na porção sul da sinclinal e, por consequência, capturar para si parte das drenagens que haviam sido pirateadas para o Rio Santo Antônio. Deste modo, após essa segunda captura, a bacia de drenagem do Rio Santo Antônio perdeu toda a porção centro e sul da sinclinal da Chapada Diamantina-Serra do Sincorá e se tornou uma bacia hidrográfica de menor dimensão e afluente de seu antigo tributário: o Rio Paraguaçu (Fig. 7).

Ressalta-se que embora não tenham sido realizadas pesquisas no divisor hidrográfico entre as bacias do Rio São Francisco e a do Rio de Contas, a morfologia local (vertentes e rede de drenagem) indica que este último também rompeu as escarpas da Serra do Espinhaço Setentrional e pirateou áreas do primeiro. $\mathrm{O}$ fato das bacias atlânticas que drenam a Serra do Espinhaço a norte conseguirem romper suas escarpas com maior facilidade que aquelas localizadas mais ao sul, parece estar relacionado a litologia, pois os metaarenitos são menos resistentes frente a erosão/ denudação do que os quartzitos. 


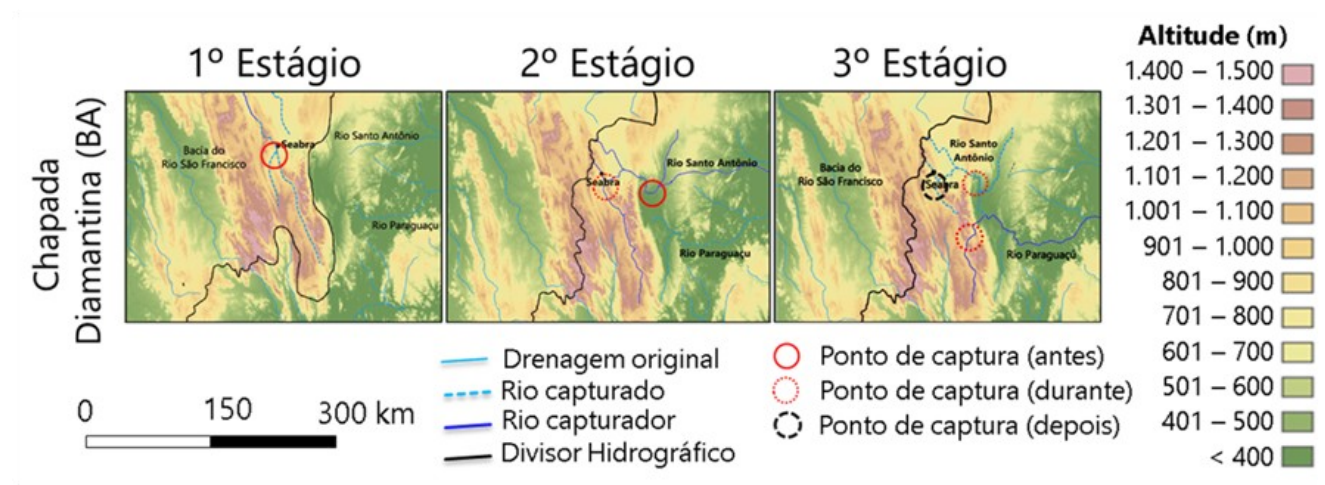

Fig. 7. Evolução temporal das capturas de drenagem na região da Chapada Diamantina-Serra do Sincorá (Serra do Espinhaço Meridional).

Fig. 7. Temporal evolution of the drainage captures in the Chapada Diamantina-Serra do Sincorá region (Southern Mountain do Espinhaço).

\section{CONSIDERAÇÕES FINAIS}

A síntese aqui apresentada dos processos de pirataria fluvial demonstra que capturas de escala meso (superiores a dezenas de quilômetros quadrados) e macro (superiores a centenas de quilômetros quadrados) são comuns nos principais interflúvios do Brasil e merecem ser mais bem investigadas. Muito mais que o clima, o nível de base (em parte dependente da tectônica) e a litoestrutura parecem ser os fatores determinantes para que elas ocorram. Neste contexto, as bacias que possuem seu piso, topograficamente, mais baixo do que a de suas vizinhas, tendem a piratear áreas delas. Paralelamente, rochas mais frágeis frente ao intemperismo e erosão costumam a não constituir obstáculo para processos de captura fluvial. No outro extremo, bacias agressivas quando confrontadas com interflúvios resistentes quartzitos, itabiritos etc - podem não conseguir realizar proeminentes processos de pirataria fluvial.

Em termos espaciais destaca-se o fato de que as bacias hidrográficas continentais do Brasil que se localizam nas proximidades do litoral - Paraná e São Francisco - estão perdendo áreas para as ditas Atlânticas - Itajaí-Açu, Paraíba do Sul, Doce, Jequitinhonha, Contas e Paraguaçu. Este processo colabora para a regressão do escarpamento de margem passiva da América do Sul e, paralelamente, é extremamente efetivo para o desmonte erosivo dos planaltos que predominam nas porções sul, sudeste e nordeste do país.

Por fim, as capturas podem ocorrer por recuo de escarpamentos ou por interceptação de canais. Em ambos os casos elas se caracterizam em um primeiro momento por um aprofundamento da rede de drenagem capturada, seguido do aumento da erosão das vertentes e rebaixamento geral do relevo pirateado. Concomitantemente a esses processos, não são raras as inversões de fluxo dos canais não pirateados localizados à jusante da captura. Isto ocorre em função de que o rebaixamento do relevo inverte a topografia local e redireciona o fluxo não capturado, ampliando, assim, a área pirateada.

\section{AGRADECIMENTOS}

Agradecemos ao apoio financeiro de diversos projetos. Em especial aos do CNPq (Universal 441501/20141 e 462421/2014-7; Produtividade em Pesquisa 302133/2012 -7 e 301727/2015-5) e ao da CAPES-COFECUB (869-15).

\section{REFERÊNCIAS}

AB'SABER, A. N. 1957. O problema das conexões antigas e da separação da drenagem do Paraíba e do Tietê. Geomorfologia, São Paulo, Instituto de Geografia da USP, v. 26, p. 38-49.

AlmeidA-Abreu, P. A.; Renger, F. E. 2002. Serra do Espinhaço meridional: um orógeno de colisão do mesoproterozóico. Revista Brasileira de Geociências, v. 32, n.1, p. 1-14.

Almeida, F. F. M.; Hasui Y.; PonÇano W. L.; Dantas A. S. L., Carneiro C. D. R.; Melo M. S.; Bistrichi C. A. 1981. Mapa Geológico do Estado de São Paulo, escala 1:500.000, Nota Explicativa. São Paulo, IPT, Monografias 6, v. 1, p.126. (Publ. 184).

Barreto, H. N.; Varajao, C. A. C.; Braucher, R.; BourLÉS, D.; SAlgado, A. A. R. 2013. Denudation rates of the Southern Espinhaço Range, Minas Gerais Brazil, determined by in situ-produced cosmogenic beryllium-10. Geomorphology, v. 191, p. 1-13.

Castanheira, M. V. S.; Freitas, M. M. \& Sarti, T. P. 2006. Evolução da rede de drenagem controlada por nível de base regional e evidências do processo de captura fluvial no médio vale do rio Paraíba do Sul VI Simpósio Nacional de Geomorfologia/ Regional Conference on Geomorphology, p. 1-10.

Cherem, L. F. ; VArajão, C.A.C. ; Braucher, R ; BourLÈs D. ; SAlgado, A. A. R. ; VARAJão, A.F.D. 2012. Long-term evolution of denudational escarpments in southeastern Brazil. Geomorphology, v. 173, p. 118-127. 
Cherem, L.F.S; Varajao, C. A. C.; Magalhaes Junior, A. P.; Varajao, A. F. D. C.; Salgado, A. A. R.; Oliveira, L. A. F.; Bertolini, W. Z. 2013. O papel das capturas fluviais na morfodinâmica das bordas interplanálticas do sudeste do Brasil. Revista Brasileira de Geomorfologia, v. 14, p. 299-308.

Cordeiro, C. M. 2017. Evolução Tércio-Quaternária do relevo da Chapada Diamantina/BA a partir das capturas fluviais. Qualificação de Doutorado Universidade Federal de Minas Gerais.

GontiJo, A. H. F. 1999. Morfometria do Médio Vale do Rio Paraíba do Sul: região da Serra da Bocaina, Estados de São Paulo e Rio de Janeiro. Tese (Doutorado) Instituto de Geociências e Ciências Exatas Universidade Estadual Paulista, 259p.

Lima, C.C.U.; Nolasco, M.C. 2015. Chapada Diamantina: A Remarkable Landscape Dominated by Mountains and Plateaus. In: Vieira, B.C.; Salgado, A.A.R.; Santos, L.J.C. (org.). World Geomorphological Landscapes. 1ed.Houten: Springer Netherlands, v. 2, p. 211-220.

Magalhães-Junior, A. P.;Barros, L.F.B. ; FelipPe, M.F. 2015.Southern Serra do Espinhaço: The Impressive Plateau of Quartzite Ridges. In: Vieira, B.C.; Salgado, A.A.R.; Santos, L.J.C. (org.). World Geomorphological Landscapes. 1ed.Houten: Springer Netherlands, v. 2, p. 359-370.

OLIVEIRA, L.A.F. 2012. A dinâmica fluvial quaternária e a configuração do modelado do relevo no contato entre a Depressão do Rio Pomba e o Planalto de Campos das Vertentes - Zona da Mata de Minas Gerais. Dissertação (Mestrado) - Programa de PósGraduação em Geografia, Instituto de Geociências Universidade Federal de Minas Gerais, 224p.

OliveIRA, D.; QueIroz Neto, J. P. 2007.Evolução do relevo na Serra do Mar no Estado de São Paulo a partir de uma captura fluvial. Geousp, São Paulo, v. 22, p. 73-88.
Salgado, A. A. R.; Sobrinho, L.C.; Cherem, L. F.; Varajão, C. A. C.; Varajão, C. A. C.; Bourlès, Didier L.; Braucher, R.; MARENT, B. R. 2012. Estudo da evolução da escarpa entre as bacias do Doce/Paraná em Minas Gerais através da quantificação das taxas de desnudação. Revista Brasileira de Geomorfologia, v. 13, p. 213-222.

Salgado, A. A. R. Bueno, G.T.; Duarte, A.; Marent, B.R. 2015. Long-Term Geomorphological Evolution of the Brazilian Territory. In: Vieira, B.C. Salgado, A.A.R.; Santos, L.J.C. (org.). World Geomorphological Landscapes. 1ed.Houten Springer Netherlands, 2015, v. 1, p. 19-31.

Santos, M. 1999. Serra da Mantiqueira e Planalto do Alto Rio Grande: a bacia terciária de Aiuruoca e evolução morfotectônica.Tese (Doutorado) Instituto de Geociências e Ciências Exatas, UNESP, Rio Claro, São Paulo.

Sordi, M.V.; SAlgado, A.A.R.; PAISANI, J.C. 2015. Evolução do relevo em áreas de tríplice divisor de águas regional - o caso do Planalto de Santa Catarina. Revista Brasileira de Geomorfologia, v. 16 , n. 3 , p. $435-447$.

Sordi, M.V.; SAlgado, A.A.R.; PAISANI, J.C. 2015 Evolução do relevo em áreas de tríplice divisor de águas regional - o caso do Planalto de Santa Catarina: análise morfoestrutural. Revista Brasileira de Geomorfologia, v. 16, n. 4, p.579-592.

Sordi, M.V.; SAlgado, A.A.R.; PAISANI, J.C. 2016. Compartimentação geomorfológica em áreas de tríplice divisor de águas regional - o caso do planalto de Santa Catarina. Geociencias v. 35, n. 4, p.623-641.

STRAHLER, A. N. 1957. Quantitative analysis of watershed geomorphology. Transactions of the American Geophysical Union, v. 38, n. 6, p. 931.920.

Summerfield, M. A. 1991. Global Geomorphology. John Wiley and Sons, New York, 537p. 